\title{
Effects of a polymorphism in the GFAP promoter on the age of onset and ambulatory disability in late-onset Alexander disease
}

\author{
Tomokatsu Yoshida ${ }^{1}$, Ikuko Mizuta ${ }^{1}$, Kozo Saito ${ }^{1}$, Ryo Ohara ${ }^{1}$, Hiroshi Kurisaki ${ }^{2}$, Keiko Ohnari ${ }^{3}$, \\ Yuichi Riku ${ }^{4}$, Yuichi Hayashi ${ }^{5}$, Hidekazu Suzuki ${ }^{6}$, Hiroaki Shii ${ }^{7}$, Yasuhiro Fujiwara ${ }^{8}$, Tadahiro Yonezu ${ }^{9}$, \\ Akiko Nagaishi ${ }^{10}$ and Masanori Nakagawa ${ }^{1}$
}

\begin{abstract}
Alexander disease $(\mathrm{AxD})$ is a rare neurodegenerative disorder. Most patients with $\mathrm{AxD}$ have a de novo dominant missense mutation in the glial fibrillary acidic protein (GFAP) gene. Patients with late-onset AxD exhibit a more variable onset and severity than patients with early-onset $A x D$, suggesting the existence of factors that modify the clinical phenotype of late-onset AxD. A -250-bp C/A single-nucleotide polymorphism (SNP) of the GFAP promoter (rs2070935) in the activator protein-1 binding site is a candidate factor for modification of the clinical phenotype. We analyzed the SNP in 10 patients with late-onset AxD and evaluated the effects of the SNP on the clinical course of late-onset AxD. Three of four cases with the C/C genotype lost the ability to walk in their 30 s or 40 s, whereas all six cases with the other genotypes retained the ability to walk throughout their 30s. The age of onset in patients with the $\mathrm{C} / \mathrm{C}$ genotype was significantly earlier than in patients with the other genotypes $(P<0.05)$. A more severe phenotype was observed in the patient in whom the $C$ allele of rs 2070935 was in cis with the GFAP mutation compared with the patient in whom the C allele of rs2070935 was in trans with the GFAP mutation. Our investigation revealed the possibility that the C/C genotype at rs2070935 of the GFAP promoter in late-onset AxD was associated with an earlier onset and a more rapid progression of ambulatory disability compared with the other genotypes. Journal of Human Genetics (2013) 58,635-638; doi:10.1038/jhg.2013.83; published online 1 August 2013
\end{abstract}

Keywords: Alexander disease; genetics; glial fibrillary acidic protein; promoter; single-nucleotide polymorphism

\section{INTRODUCTION}

Alexander disease $(\mathrm{AxD})$ is a rare neurodegenerative disorder characterized by white matter degeneration and the formation of cytoplasmic inclusions known as Rosenthal fibers, which primarily accumulate in the astrocyte end-feet in the subpial and perivascular zones and consist of glial fibrillary acidic protein (GFAP), heat-shock protein 27 and $\alpha \mathrm{B}$-crystallin. ${ }^{1-3}$ Since 2001 , studies have reported GFAP mutations in various clinical types of AxD. ${ }^{4}$ Although most of the mutations in the coding region of GFAP in patients with $\mathrm{AxD}$ are missense mutations, additions and/or deletions of one or a few amino acids and intronic mutations that result in frame shifts have also been identified. ${ }^{5}$ These mutations are expected to have dominant gain-offunction and dominant-negative effects. ${ }^{4,6}$

$\mathrm{AxD}$ has been classified according to the age of onset into the following three subtypes: infantile $\mathrm{AxD}$ ( $<2$ years of age), juvenile
$\mathrm{AxD}$ (2-12 years of age) and adult $\mathrm{AxD}$ ( $>12$ years of age). However, we recently proposed a novel classification of $\mathrm{AxD}$ into three distinct types based on neurological and magnetic resonance imaging findings: cerebral (type 1), bulbospinal (type 2) and intermediate (type 3). ${ }^{7,8}$ Late-onset $\mathrm{AxD}$, which includes types 2 and 3, exhibits a more variable onset and severity in comparison with early-onset $\mathrm{AxD}$, which includes type 1 , suggesting the existence of factors that modify the clinical phenotype, particularly of types 2 and $3 .^{9-11}$

A single-nucleotide polymorphism (SNP) in the activator protein-1 binding site of the GFAP promoter, $-250 \mathrm{bp}$ upstream from the GFAP transcriptional start site (NCBI dbSNP: rs2070935), is a candidate factor for mediating the effects of GFAP mutations. ${ }^{12}$ The A allele at rs2070935, which is a minor allele with an allelic frequency of 0.43 , would primarily modify the site sequence and create a novel activator protein-1 binding site. An investigation of healthy controls

\footnotetext{
${ }^{1}$ Department of Neurology, Graduate School of Medical Science, Kyoto Prefectural University of Medicine, Kyoto, Japan; ${ }^{2}$ Department of Neurology, National Hospital Organization, Tokyo National Hospital, Tokyo, Japan; ${ }^{3}$ Department of Neurology, University of Occupational and Environmental Health School of Medicine, Fukuoka, Japan; ${ }^{4}$ Department of Neurology, Nagoya University Graduate School of Medicine, Nagoya, Aichi, Japan; ${ }^{5}$ Department of Neurology and Geriatrics, Gifu University Graduate School of Medicine, Gifu, Japan; ${ }^{6}$ Department of Neurology, Kinki University School of Medicine, Osaka, Japan; ${ }^{2}$ Department of Neurology, Kokura Memorial Hospital, Fukuoka, Japan; ${ }^{8}$ Department of Neurology, Matsushita Memorial Hospital, Osaka, Japan; ${ }^{9}$ Department of Neurology, Graduate School of Medicine, Chiba University, Chiba, Japan and 10Department of Neurology, National Hospital Organization, Nagasaki Kawatana Medical Center, Nagasaki, Japan

Correspondence: Dr T Yoshida, Department of Neurology, Graduate School of Medical Science, Kyoto Prefectural University of Medicine, Kawaramachi Hirokoji, Kajii-chou 465, Kamigyo-ku, Kyoto 602-0841, Japan.
}

E-mail: toyoshid@koto.kpu-m.ac.jp

Received 7 March 2013; revised 18 June 2013; accepted 9 July 2013; published online 1 August 2013 
has revealed that, based on differences in the extent of binding between $\mathrm{C}$ and $\mathrm{A}$ alleles, the $\mathrm{C}$ allele has a greater association with transcriptional activity than the A allele. ${ }^{12}$ These results indicate higher levels of GFAP expression in the presence of the $\mathrm{C}$ allele than in that of the A allele. ${ }^{12}$

In this study, to evaluate whether rs2070935 affected the clinical course of late-onset AxD, we analyzed the SNP in the GFAP promoter and examined the relationship between the SNP, age of onset and ambulatory disability in patients with $\mathrm{AxD}$ that was classified as types 2 and 3 .

\section{MATERIALS AND METHODS}

\section{Gene analysis}

Between 2005 and 2012, to analyze GFAP mutations, 44 patients suspected of having AxD were referred to Kyoto Prefectural University of Medicine from other hospitals all over Japan. Genomic DNA was extracted from the peripheral blood of all patients after obtaining their informed consent. To detect GFAP mutations, sequence analysis of genomic DNA was performed as described previously. ${ }^{13}$ Point mutations in GFAP were identified in 12 of these patients. Of these, six satisfied the criteria of our proposed novel classification for type $2 \mathrm{AxD}$, and four satisfied the criteria for type $3 \mathrm{AxD}$. These 10 patients were included in this study.

The genomic DNA containing rs2070935 was amplified using polymerase chain reaction (PCR) with the following primers: forward, $5^{\prime}$-GTCCCCAGTTCATAGCAGGA-3'; reverse, $5^{\prime}$-GTGATGCGTCTCCTCTCCAT-3'. Direct sequence analysis was performed using an ABI PRISM 3100 autosequencer (PE Applied Biosystems, Foster City, CA, USA) and Big Dye terminators according to the manufacturer's instructions.

\section{Subcloning}

The genomic DNA containing the coding region of rs2070935 and codon 74 of the GFAP exon 1, with a PCR product size of $803 \mathrm{bp}$, was amplified using PCR with the following primers: forward, $5^{\prime}$-ACTCAGCCCTTTCCTTCCTT- $3^{\prime}$; reverse, 5'-CAGATTGTCCCTCTCAACCTCC- $3^{\prime}$. The PCR products subjected to the attachment of a poly-A tail $(10 \times \mathrm{A}$-attachment mix $)$ were ligated into pGEM-T Easy Vector (Promega, Madison, WI, USA), and subsequently transformed into chemically competent Escherichia coli cells. After screening for successful insertion using Insert Check Ready (Toyobo, Osaka, Japan), direct sequence analysis of three clones for each PCR product was performed as described above.

\section{Phenotype-genotype correlation}

We evaluated the age of onset and the age of ambulatory disability among patients with the $\mathrm{C} / \mathrm{C}, \mathrm{C} / \mathrm{A}$ and $\mathrm{A} / \mathrm{A}$ genotypes. Furthermore, ambulatory disability was evaluated by constructing the Kaplan-Meier ambulatory curves of $\mathrm{C} / \mathrm{C}$ versus $\mathrm{C} / \mathrm{A}$ and $\mathrm{A} / \mathrm{A}$ genotypic patients. The statistical analysis of the relationship between the SNP and age of onset was performed by EkuseruToukei 2010. A $P$-value $<0.05$ was considered statistically significant.

\section{RESULTS}

In 10 patients with type 2 or $3 \mathrm{AxD}$, we identified the following rs2070935 genotypes: four C/C homozygotes, five C/A heterozygotes and one $\mathrm{A} / \mathrm{A}$ homozygote (Table 1). Of four patients with the $\mathrm{C} / \mathrm{C}$ genotype, three had lost the ability to walk in their $30 \mathrm{~s}$ or $40 \mathrm{~s}$; however, all six patients with the C/A or A/A genotypes retained the ability to walk throughout their $30 \mathrm{~s}$ (Figure 1). The mean age of onset in the patients with the $\mathrm{C} / \mathrm{C}$ genotype was 9.5 years and that in patients with $\mathrm{C} / \mathrm{A}$ and $\mathrm{A} / \mathrm{A}$ genotypes was 40.2 years old $(P<0.05)$. An $\mathrm{R} 79 \mathrm{H}$ GFAP mutation was observed in three patients with the following rs2070935 genotypes: A/A homozygote (patient 7), C/C homozygote (patient 8 ) and $\mathrm{C} / \mathrm{A}$ heterozygote (patient 10). Patient 8 with the $\mathrm{C} / \mathrm{C}$ genotype exhibited earlier onset than patients 7 and 10

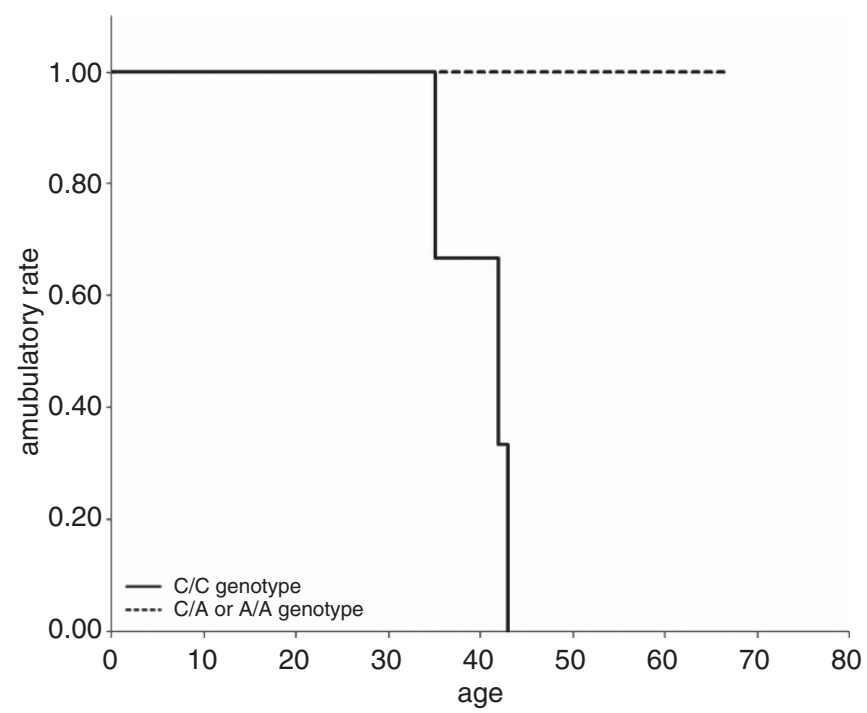

Figure 1 Ambulatory disability was evaluated by constructing the KaplanMeier ambulatory curves of $\mathrm{C} / \mathrm{C}$ versus $\mathrm{C} / \mathrm{A}$ and $\mathrm{A} / \mathrm{A}$ genotypic patients.

Table 1 Clinical and genetic data in 10 patients of AxD

\begin{tabular}{|c|c|c|c|c|c|c|c|c|}
\hline $\begin{array}{l}\text { Patient } \\
\text { number }\end{array}$ & Sex & $\begin{array}{l}\text { Age of gene } \\
\text { analysis (y.o.) }\end{array}$ & $\begin{array}{c}\text { Age of onset } \\
(\text { y.o. })\end{array}$ & Clinical type ${ }^{a}$ & First symptom & $\begin{array}{c}\text { Age of ambulatory } \\
\text { disability (y.o.) }\end{array}$ & $\begin{array}{c}\text { GFAP mutation } \\
\text { (ref.) }\end{array}$ & $\begin{array}{l}-250 b p \\
\text { Genotype }\end{array}$ \\
\hline 1 & $\mathrm{M}$ & 67 & 64 & Type 2 & Dysphagea & None & R70W13 & $\mathrm{C} / \mathrm{A}$ \\
\hline 2 & $\mathrm{M}$ & 56 & 51 & Type 2 & Gait disturbance & None & $\mathrm{M} 74 \mathrm{~T}^{14}$ & $\mathrm{C} / \mathrm{A}$ \\
\hline 3 & $\mathrm{M}$ & 53 & 51 & Type 2 & Dysarthria & None & $\mathrm{M} 74 \mathrm{~T}^{13,30}$ & $\mathrm{C} / \mathrm{A}$ \\
\hline 4 & $M$ & 24 & 18 & Type 2 & Gait disturbance & None & $\mathrm{L}^{357 \mathrm{P}^{13}}$ & $\mathrm{C} / \mathrm{C}$ \\
\hline 5 & $\mathrm{M}$ & 58 & 12 & Type 2 & Gait disturbance & $30 s$ & E362G & $\mathrm{C} / \mathrm{C}$ \\
\hline 6 & $\mathrm{~F}$ & 31 & 1 & Type 3 & Convulsion & None & V87L 31 & $\mathrm{C} / \mathrm{A}$ \\
\hline 7 & $M$ & 37 & 36 & Type 3 & Gait disturbance & None & $\mathrm{R} 79 \mathrm{H}^{13}$ & $A / A$ \\
\hline 8 & $\mathrm{~F}$ & 51 & 5 & Type 3 & Gait disturbance & 43 & $\mathrm{R} 79 \mathrm{H}$ & $\mathrm{C} / \mathrm{C}$ \\
\hline 9 & $\mathrm{~F}$ & 47 & 3 & Type 3 & Encephalitis & 42 & A268D & $\mathrm{C} / \mathrm{C}$ \\
\hline 10 & $\mathrm{~F}$ & 40 & 38 & Type 3 & Gait disturbance & None & $\mathrm{R} 79 \mathrm{H}^{32}$ & $\mathrm{C} / \mathrm{A}$ \\
\hline
\end{tabular}

Abbreviations: AxD, Alexander disease; F, female; GFAP, glial fibrillary acidic protein; M, male; y.o., years old.

aType 2 = bulbospinal AxD; type $3=$ intermediate form AxD. 
Table 2 Comparison of clinical data among three patients with R79H AxD

\begin{tabular}{|c|c|c|c|}
\hline & Patient 7 & Patient 8 & Patient 10 \\
\hline -250 bp Genotype & A/A & $\mathrm{C} / \mathrm{C}$ & C/A \\
\hline $\begin{array}{l}\text { Age of gene analysis } \\
\text { (age of onset) }\end{array}$ & $37(36)$ & $52(5)$ & $40(38)$ \\
\hline Sex & M & $\mathrm{F}$ & $\mathrm{F}$ \\
\hline Convulsion & Infantile only & Infantile only & $\begin{array}{c}\text { Once at the } \\
\text { age of } 1\end{array}$ \\
\hline Mental retardation & + & + & - \\
\hline Macrocephaly & - & - & - \\
\hline Dysarthria & + & + & - \\
\hline Dysphagia & - & + & - \\
\hline Ataxia & + & $?$ & + \\
\hline Palatal myoclonus & - & + & - \\
\hline Muscle weakness & $\begin{array}{l}+ \text { (only lower } \\
\text { extremities) }\end{array}$ & + & - \\
\hline Hyperreflexia & - & + & - \\
\hline Babinski sign & $-1-$ & $+/+$ & $-1-$ \\
\hline Sphincter dysfunction & + & + & - \\
\hline Sleep disorder & - & + & - \\
\hline
\end{tabular}

Abbreviations: AxD, Alexander disease; F, female; $\mathrm{M}$, male.

Table 3 Comparison of clinical data between two patients with M74T

\begin{tabular}{lcc}
\hline & Patient $2^{\mathrm{a}}$ & Patient 3 \\
\hline-250 bp Genotype & $\mathrm{C} / \mathrm{A}$ & $\mathrm{C} / \mathrm{A}$ \\
Age of gene analysis (age of onset) & $56(51)$ & $53(51)$ \\
Sex & $\mathrm{M}$ & $\mathrm{M}$ \\
Convulsion & $?$ & - \\
Mental retardation & - & - \\
Macrocephaly & - & - \\
Dysarthria & + & + \\
Dysphagia & - & - \\
Ataxia & - & - \\
Palatal myoclonus & - & - \\
Muscle weakness & + & + \\
Hyperreflexia & + & $-/-$ \\
Babinski sign & $+/+$ & - \\
Sphincter dysfunction & + & - \\
Sleep disorder & - & \\
\hline
\end{tabular}

Abbreviation: $\mathrm{M}$, male.

apatient 2 required the aid of walker.

with the $\mathrm{A} / \mathrm{A}$ and $\mathrm{C} / \mathrm{A}$ genotypes, respectively. Patient 8 exhibited gait disturbance at the age of 5 years and lost the ability to walk at the age of 43 years (Table 2). In addition, in her mid-30s, she developed bulbar dysfunction, which progressed gradually. She had difficulty in swallowing and underwent a percutaneous endoscopic gastrostomy at the age of 45 years. Patients 7 and 10 did not show gait disturbance until their late $30 \mathrm{~s}$, and at the time of this study, they were able to walk and did not present with difficulties in swallowing. Although two patients (patient 2 and 3) in whom M74T (c.221-T>C) mutation was observed had the C/A genotype at rs2070935 and similar ages of onset, patient 2 showed spastic tetraparesis with muscle weakness and required the aid of a walker (Table 3). ${ }^{14}$ Gene analysis using the subcloning method revealed that the $\mathrm{C}$ allele of rs 2070935 was in cis with the gene containing the mutant allele of codon 221 in patient 2 and in trans in patient 3 .

\section{DISCUSSION}

Investigations on clinical phenotype-genotype correlations and morphological and functional impairment of astrocytes due to GFAP mutations using cells or animal models have suggested that the clinical type of $\mathrm{AxD}$ is primarily determined by the GFAP mutation. ${ }^{4,5,13,15-28}$ However, patients with late-onset $\mathrm{AxD}$, which includes types 2 and 3, exhibit variable onset and severity, suggesting the existence of other factors that modify the clinical course. ${ }^{9-11}$

An investigation using a transgenic mouse model that overexpressed wild-type GFAP has revealed that the aggregates are similar to Rosenthal fibers and that a shorter lifespan is observed in patients with increased GFAP expression, ${ }^{29}$ suggesting that GFAP overexpression may cause AxD. Although $3 \%$ of the patients with AxD did not have detectable GFAP mutations, ${ }^{15}$ other causative factors such as GFAP multiplication ${ }^{8}$ have not been detected either.

The rs2070935 in the activator protein-1 binding site of the GFAP promoter, which may mediate the effects of GFAP mutations, is a candidate factor for the modification of the clinical course of $\mathrm{AxD},{ }^{12}$ and differences in the degree of binding between $\mathrm{C}$ and $\mathrm{A}$ alleles have demonstrated a greater association of the $\mathrm{C}$ allele with transcriptional activity compared with the A allele. ${ }^{12}$

Our results suggested that the presence of the C/C genotype at rs2070935 may contribute to the early onset and the severity of ambulatory function in late-onset $\mathrm{AxD}$, supporting the findings of a previous study that demonstrated a greater association of the $\mathrm{C}$ allele with transcriptional activity compared with that of the A allele. ${ }^{12}$ Our investigation of two M74T mutations at C/A genotype at rs2070935 suggested that the patient in whom the $\mathrm{C}$ allele of rs2070935 was in cis with the GFAP mutation may show a more severe phenotype than the patient in whom the $\mathrm{C}$ allele of rs2070935 was in trans with the GFAP mutation.

Although the minor allelic frequency of the A allele in rs2070935 of the GFAP promoter is 0.43 , the C/A SNP allelic frequency differs among races, as follows: the A allelic frequency is 0.35 in Asians, 0.44 in Europeans, 0.39 in Americans and 0.54 in Africans (1000 Genomes; http://www.1000genomes.org/). Thus, the severity of AxD may differ among races. Additional studies are needed to clarify the natural history of late-onset $\mathrm{AxD}$ among races.

A limitation of our investigation was the extremely small sample size. However, it may be difficult to examine a sufficient number of subjects because $\mathrm{AxD}$ is extremely rare, with an estimated prevalence of approximately one in 2.7 million people in Japan. ${ }^{7}$ Furthermore, identical GFAP mutations in late-onset $\mathrm{AxD}$ are much rarer. $^{7}$

In conclusion, our investigation demonstrated the possibility that a $\mathrm{C} / \mathrm{C}$ genotype at rs2070935 in patients with late-onset $\mathrm{AxD}$ may be associated with an earlier onset of motor impairment and more rapid progression of ambulatory disability than the C/A and A/A genotypes at rs2070935, although larger-scale investigation and long-term evaluation are required.

\section{ACKNOWLEDGEMENTS}

This work was supported by Alexander disease research grants received from a Grant-in-Aid for Scientific Research (C) from Japan Society for the Promotion of Science (Grant number 24591273). 
1 Alexander, W. S. Progressive fibrinoid degeneration of fibrillary astrocytes associated with mental retardation in a hydrocephalic infant. Brain 72, 373-381 (1949).

2 Iwaki, T., Kume-Iwaki, A., Liem, R. K. H. \& Goldman, J. E. Alpha-B-crystallin is expressed in non-lenticular tissues and accumulates in Alexander's disease brain. Cell 57, 71-78 (1989).

3 Iwaki, T., Iwaki, A., Tateishi, J., Sasaki, Y. \& Goldman, J. E. Alpha B-crystallin and 27-kDa heat shock protein are regulated by stress conditions in the nervous system and accumulate in Rosenthal fibers. Am. J. Pathol. 143, 487-495 (1993).

4 Brenner, M., Johnson, A. B., Boespflug-Tanguy, O., Rodriguez, D., Goldman, J. E. \& Messing, A. Mutations in GFAP, encoding glial fibrillary acidic protein, are associated with Alexander disease. Nat. Genet. 27, 277-286 (2001).

5 Flint, D., Li, R., Webster, L. S., Naidu, S., Kolodny, E., Percy, A. et al. Splice site, frameshift, and chimeric GFAP mutations in Alexander disease. Hum. Mutat. 33, 1141-1148 (2012)

6 Bachetti, T., Caroli, P., Bocca, I., Prigione, P., Balbi, R., Biancheri, R. et al. Mild functional effects of a novel GFAP mutant allele identified in a familial case of adultonset Alexander disease. Eur. J. Hum. Genet. 16, 462-470 (2008),

7 Yoshida, T., Sasaki, M., Yoshida, M., Namekawa, M., Okamoto, Y., Tsujino, S. et al. Nationwide survey of Alexander disease in Japan and proposed new guidelines for diagnosis. J. Neurol. 258, 1998-2008 (2011).

8 Yoshida, T. \& Nakagawa, M. Clinical aspects and pathology of Alexander disease, and morphological and functional alteration of astrocytes induced by GFAP mutation. Neuropathology 32, 440-446 (2012).

9 Probst, E. N., Hagel, C. Weisz, V., Nagel, S., Wittkugel, O., Zeumer, H. et al Atypical focal MRI lesions in a case of juvenile Alexander's disease. Ann. Neurol. 53, 118-120 (2003).

10 van der Knaap, M. S., Salomons, G. S., Li, R., Franzoni, E., Gutiérrez-Solona, L. G., Smit, L. M. et al. Unusual variants of Alexander's disease. Ann. Neurol. 57, 327-338 (2005).

11 Niinikoski, H., Haataja, L., Brander, A., Valanne, L. \& Blaser, S. Alexander disease as a cause of nocturnal vomiting in a 7-year-old girl. Pediatr. Radiol. 39, 872-875 (2009).

12 Bachetti, T., Di Zanni, E., Lantieri, F., Caroli, F., Regis, S., Filocamo, M. et al. A novel polymorphic AP-1 binding element of the GFAP promoter is associated with different allelic transcriptional activities. Ann. Hum. Genet. 74, 506-515 (2010).

13 Yoshida, T., Sasayama, H., Mizuta, I., Okamoto, Y., Yoshida, M., Riku, Y. et al. Glial fibrillary acidic protein mutations in adult-onset Alexander disease: clinical features observed in 12 Japanese cases. Acta Neurol. Scand. 124, 104-108 (2011).

14 Yonezu, T., Ito, S., Kanai, K., Masuda, S., Shibuya, K. \& Kuwabara, S. A case of adultonset Alexander disease featuring severe atrophy of the medulla oblongata and upper cervical cord on magnetic resonance imaging. Case Rep. Neurol. 4, 202-206 (2012)

15 Gorospe, J. R. in GeneReviews ${ }^{\mathrm{TM}}$ [Internet] Pagon, R. A., Bird, T. D., Dolan, C. R. Stephens, K. \& Adam, M. P. (eds) (University of Washington, Seattle, WA, 1993-2002) (updated 22 April 2010).

16 Prust, M., Wang, J., Morizono, H., Messing, A., Brenner, M., Gordon, E. et al. GFAP mutations, age at onset, and clinical subtypes in Alexander disease. Neurology 77 1287-1294 (2011)

17 Farina, L., Pareyson, D., Minati, L., Ceccherini, I., Chiapparini, L., Romano, S. et al. Can MR imaging diagnose adult-onset Alexander disease? Am J Neuroradiol. 29 1190-1196 (2008).
18 Pareyson, D., Fancellu, R., Mariotti, C., Romano, S., Salmaggi, A., Carella, F. et al. Adult-onset Alexander disease: a series of eleven unrelated cases with review of the literature. Brain 131, 2321-2331 (2008).

19 Balbi, P., Salvini, S., Fundarò, C., Frazzitta, G., Maestri, R., Mosah, D. et al. The clinical spectrum of late-onset Alexander disease: a systematic literature review. J. Neurol. 257, 1955-1962 (2010).

20 Li, R., Johnson, A. B., Salomons, G., Goldman, J. E., Naidu, S., Quinlan, R. et al. Glial fibrillary acidic protein mutations in infantile, juvenile, and adult forms of Alexander disease. Ann. Neurol. 57, 310-326 (2005).

21 Hsiao, V. C., Tian, R., Long, H., Perng, M. D., Brenner, M., Quinlan, R. A. et al. Alexander-disease mutation of GFAP causes filament disorganization and decreased solubility of GFAP. J. Cell. Sci. 118, 2057-2065 (2005).

22 Perng, M. D., Su, M., Wen, S. F., Li, R., Gibbon, T., Prescott, A. R. et al. The Alexander disease-causing glial fibrillary acidic protein mutant, R416W, accumulates into Rosenthal fibers by a pathway that involves filament aggregation and the association of $\alpha$ B-crystallin and HSP27. Am. J. Hum. Genet. 79, 197-213 (2006).

23 Tang, G., Xu, Z. \& Goldman, J. E. Synergistic effects of the SAPK/JNK and the proteasome pathway on glial fibrillary acidic protein (GFAP) accumulation in Alexander disease. J. Biol. Chem. 281, 38634-38643 (2006).

24 Tang, G., Yue, Z., Talloczy, Z., Hagemann, T., Cho, W., Messing, A. et al. Autophagy induced by Alexander disease-mutant GFAP accumulation is regulated by p38/MAPK and mTOR signaling pathways. Hum. Mol. Genet. 17, 1540-1555 (2008).

25 Tang, G., Perng, M. D., Wilk, S., Quinlan, R. \& Goldman, J. E. Oligomers of mutant glial fibrillary acidic protein (GFAP) inhibit the proteasome system in Alexander disease astrocytes, and the small heat shock protein $\alpha \mathrm{B}$-crystallin reverses the inhibition. J. Biol. Chem. 285, 10527-10537 (2010).

26 Hagemann, T. L., Gaeta, S. A., Smith, M. A., Johnson, D. A., Johnson, J. A. \& Messing, A Gene expression analysis in mice with elevated glial fibrillary acidic protein and Rosenthal fibers reveals a stress response followed by glial activation and neuronal dysfunction. Hum. Mol. Genet. 14, 2443-2458 (2005).

27 Hagemann, T. L., Boelens, W. C., Wawrousek, E. F. \& Messing, A. Suppression of GFAP toxicity by $\alpha \mathrm{B}$-crystallin in mouse models of Alexander disease. Hum. Mol. Genet. 18, 1190-1199 (2009)

28 Wang, L., Colodner, K. J. \& Feany, M. B. Protein misfolding and oxidative stress promote glial-mediated neurodegeneration in an Alexander disease midel. J. Neurosci. 31, 2868-2877 (2011).

29 Messing, A., Head, M. W. \& Galles, K. Fatal encephalopathy with astrocyte inclusions in GFAP transgenic mice. Am. J. Pathol. 152, 391-398 (1998).

30 Ohnari, K., Yamano, M., Uozumi, T., Hashimoto, T., Tsuji, S. \& Nakagawa, M. An adult form of Alexander disease: novel mutation in glial fibrillary acidic protein. J. Neurol. 254, 1390-1394 (2007).

31 Suzuki, H., Yoshida, T., Kitada, M., Ichihashi, J., Sasayama, H., Nishikawa, Y. et al. Late-onset Alexander disease with a V87L mutation in glial fibrillary acidic protein (GFAP) and calcifying lesions in the sub-cortex and cortex. J. Neurol. 259, 457-461 (2012).

32 Nagaishi, A., Nakane, S., Fukudome, T., Matsuo, H. \& Yoshida, T. A case of Alexander disease suspected juvenile-onset and exacerbating after long stationary state. Clin. Neurol. 53, 474-477 (2013). 